\title{
DISCURSOS MORAIS NO \\ PERIÓDICO “FOLHA DA ESCOLA" (1940): \\ REPRESENTAÇÕES INFANTIS
}

\author{
MORAL SPEECHES AT "FOLHA \\ DA ESCOLA" JOURNAL (1940): CHILD \\ REPRESENTATION
}

\author{
Milena Aragão ${ }^{1}$ \\ Anamaria Gonçalves Bueno de Freitas ${ }^{2}$
}

\begin{abstract}
Resumo: O presente artigo investiga os discursos morais contidos em redações elaboradas por crianças entre nove e 11 anos de idade, publicadas no periódico "Folha da Escola" (1940), jornal editado pela Escola Complementar Duque de Caxias (1930). Os textos redigidos pelas crianças perpassam a temática da obediência, sinalizando consequências quanto ao não cumprimento das ordens. Tais discursos foram analisados partindo de dois eixos: conteúdo e publicação, tendo como base um diálogo com alguns dos grandes pensadores da educação que advogavam a importância da educação moral no desenvolvimento infantil como Durkheim, Herbart, Spencer, Condorcet e Norbert Elias. O texto está organizado de modo a contextualizar a Escola Complementar Duque de Caxias, seguido de considerações sobre a cultura escolar e cultura material escolar. Posteriormente, há o mergulho nas escritas infantis, com suas análises à luz dos pensadores supracitados.
\end{abstract}

Palavras-chave: Cultura Escolar. Discurso Moral. Educação. Escrita infantil. Periódico.

Abstract: This paper investigates the moral speeches contained in essays compiled by children between nine and eleven years old, published in the journal "Folha da Escola" (1940), newspaper published by Normal School Duque de Caxias (1930). The texts written by the children pervades 
the theme of obedience. Such speeches were analyzed based on two axs: content and publication, based on a dialog with some of the great thinkers of education who advocated the importance of moral education in child development, such as Durkheim, Herbart, Spencer, Condorcet and Norbert Elias. The paper is organized so as to contextualize the School Duque de Caxias, followed by considerations about the school culture and material school culture. In the second part, the infant written is analyzed in light of thinkers pointed above.

Keywords: Child Written. Education. Journal. Moral Discourse. School Culture. 


\section{Palavras iniciais}

Em diferentes tempos históricos, fábulas, contos de fadas, parábolas, enfim, uma série de contos populares foi elaborada com o objetivo de ensinar valores importantes para a vida em sociedade. Como esquecer as fábulas de Esopo ou de La Fontaine, os contos dos irmãos Grimm, Charles Perrault e até Monteiro Lobato? Histórias de cunho moral são encontradas em livros didáticos e infantis, disseminados tanto nas escolas quanto pela família. Reuniões em torno da mesa para ouvir os contos da avó, as histórias antes de dormir, a hora do conto nas aulas de educação infantil... exemplos não faltam.

Todavia, este artigo não aborda as histórias que os adultos contam para as acrianças, mas o quê - dessas histórias contadas - as crianças introjetam e reproduzem em forma de redação. Sobre que temas elas escrevem? O que comunicam?

Foi realizada, portanto, uma investigação nos discursos contidos em redações elaboradas por crianças entre nove e onze anos de idade, publicadas no periódico "Folha da Escola" (1940), jornal editado pela Escola Complementar Duque de Caxias (1930), de circulação regional, ultrapassando, assim, os muros da escola. Partindo do princípio que nenhum texto é inócuo, é questionada a intencionalidade na divulgação de tais redações e, ainda, o motivo da escolha dos temas publicados.

A Escola Complementar Duque de Caxias foi inaugurada no município de Caxias do Sul (RS) em 28 de fevereiro de 1930 com um duplo fim: desenvolver o ensino elementar e preparar os professores para a carreira do magistério. Na década de 1940, por força do Decreto n. 775, de 15 de maio de 1943, a Escola Complementar muda seu nome para Escola Normal Duque de Caxias e em 23 de janeiro de 1959 (em decorrência do Decreto Estadual n. 10045) a Escola muda mais uma vez sua designação, passando a Colégio Estadual Cristóvão de Mendoza, em 
homenagem ao introdutor do gado no Rio Grande do Sul, Padre Cristóvão de Mendoza, permanecendo com essa nomenclatura até os dias atuais (BERGOZZA, 2010).

Vale ressaltar que, com o intuito de colaborar com mais vigor para a promoção de uma educação libertadora e participativa, a Escola Complementar cria três veículos de comunicações internas, a partir de 1932: jornal "A voz da Mocidade"; jornal "Folha da Escola" e jornal "Centelha". Todavia, para a produção deste texto será utilizado o jornal "Folha da Escola", tendo em vista constar apenas neste a publicação das redações infantis (BERGOZZA, 2010).

Desta forma, o presente artigo analisará as redações transcritas partindo de dois eixos: seu conteúdo e sua publicação, tendo como base um diálogo com alguns dos grandes pensadores da educação que advogavam a importância da educação moral no desenvolvimento infantil como Durkheim, Herbart, Spencer, Condorcet e Norbert Elias ${ }^{3}$.

O texto está organizado de modo a contextualizar a Escola Complementar Duque de Caxias, seguido de considerações sobre a cultura escolar e cultura material escolar. Posteriormente, há o mergulho nas escritas infantis, com suas análises à luz dos pensadores supracitados.

\section{Os primeiros passos na formação docente: contextualizando a "Duque"}

Em solo Brasileiro, a primeira Escola Normal foi inaugurada no ano de 1835, em Niterói (RJ). A partir de então, cerca de 15 estados abriram as portas para o ensino de professores até o ano de 1890, todavia, com trajetórias efêmeras e conturbadas (VEIGA, 2007). 
À medida que surgiam escolas no Brasil para formar mestres, Caxias do Sul (RS) ainda construía sua existência como cidade, o que ocorreu em 1920, 45 anos após a chegada do primeiro imigrante italiano à região serrana do Rio Grande do Sul. Pouco antes da imigração italiana em solo gaúcho, Porto Alegre (RS) já havia inaugurado sua primeira Escola Normal, em 1869 (ANTUNES, 1950).

Apesar de Caxias do Sul sequer ser urbanizada quando as Escolas Normais surgiam no país, seu desenvolvimento ocorreu de forma considerável, passando da agricultura de subsistência para uma industrialização a nível doméstico que, diversificada e seguindo o crescimento populacional, desenvolveu para um importante parque industrial (ANTUNES, 1950).

Tal desenvolvimento foi acompanhado de perto pelo cenário educativo. Na primeira década do século XX, funcionavam 28 aulas públicas, além de professores particulares e escolas religiosas de muita representatividade, como o Ginásio São José (1901) e o Ginásio Nossa Senhora do Carmo (1908), por exemplo (ANTUNES, 1950).

A expansão urbana, comercial e industrial da cidade, a qual demandava pessoas qualificadas para o trabalho, associada ao estabelecimento e expansão das Escolas Normais no país, impulsionou a abertura, em 19304, da Escola Complementar de Caxias do Sul, destinada à formação de professores primários. Vale salientar que as escolas complementares foram criadas em solo gaúcho no ano de 1906, por Borges de Medeiros, presidente do Estado, a fim de preparar professores para a escola primária elementar e pública. Sua função primordial era desenvolver o ensino elementar, ao mesmo tempo em que preparava para o exercício docente. A primeira escola complementar foi aberta em Porto Alegre, e, posteriormente, foram inauguradas em diversas cidades no interior do Estado (ANTUNES, 1950; BERGOZZA, 2010) 
A inauguração da "Duque" ocorreu num período histórico de renovação pedagógica. John Dewey (1859-1952), filósofo e pedagogo, já defendia a educação como necessidade social, sendo um dos precursores do movimento Escola Nova, que chegou ao Brasil na década de 1930, corroborado por Anísio Teixeira (1900-1971), Lourenço Filho (1897-1970) e Fernando de Azevedo (1894-1974). Os pensadores escolanovistas acreditavam na transformação social por meio da educação, propondo a modificação de técnicas de ensino e a escolarização laica e gratuita. Em linhas gerais, este movimento defendia a educação como elemento eficaz para a construção de uma sociedade democrática, formando cidadãos atuantes, capazes de debater e refletir sobre si e seu papel no mundo (CAMBI, 1999).

A Escola Complementar Duque de Caxias ${ }^{5}$, imersa neste contexto, foi fundada com o intuito de democratizar o ensino e a formação de professores, seguindo as bases escolanovistas, tendo como lema: "Educar-se para educar", por isso, preocupavase com a criação de três periódicos internos, a fim de contribuir com a promoção de uma educação libertadora e participativa.

\section{Abrindo os portões da escola: considerações sobre cultura escolar}

Lema é uma palavra utilizada para resumir as características de algo, podendo ser um lugar, um produto ou até mesmo uma pessoa. Ela expressa valores, conceitos, sentimentos, comportamentos, representações, identidades. Neste sentido, é possível aferir que o lema escolhido para representar a Escola Complementar Duque de Caxias revela traços de sua cultura.

Abrir os portões de uma escola significa entrar em um universo complexo, imerso numa rede de relações e significações 
que envolve sujeitos, artefatos, tempos e espaços. Viñao Frago (1995, p. 69) afirma que as culturas escolares são “[...] toda la vida escolar: hechos e ideas mentes y cuerpos, objetos y conductas, modos de pensar, decidir y hacer." Investigar as culturas escolares de uma determinada instituição permite-nos "[...] identificar o modo como, em diferentes momentos, uma determinada realidade social é construída, pensada, dada a ler." (CHARTIER, 2002, p. 16). Ela envolve toda a vida escolar, suas práticas, modos de ser, pensar e fazer.

Julia (2001) apresenta a cultura escolar como um importante campo de investigação em História da Educação, interpretando-a como um conjunto de normas e práticas que define os saberes a ensinar e os valores e comportamentos a inculcar. $\mathrm{O}$ autor ressalta que as culturas escolares não são estagnadas, ao contrário, estão sempre em movimento, são dinâmicas, à medida que elaboram e reelaboram suas normas e práticas sendo, ao mesmo tempo, o processo e o resultado das experiências, das práticas, das vivências dos sujeitos que fazem a escola. Desta forma, investigar a cultura escolar é estudar as práticas e os significados que permitem construção e transmissão dos conhecimentos, valores e comportamentos.

Neste sentido, para nos aproximarmos dos fazeres ordinários da escola é preciso analisar os aspectos que constroem as culturas escolares, o que inclui sua materialidade.

Conforme Souza (2007):

A expressão cultura material escolar [...] passou a ser utilizada na área da História da Educação nos últimos anos, influenciada pelos estudos em cultura escolar, pela renovação na área provocada pela Nova História Cultural e pela preocupação crescente dos historiadores em relação à preservação das fontes de pesquisa e de memória educacional em arquivos escolares, museus e centros de documentação. Ao recortar o universo da 
cultura material especificando um domínio próprio, isto é, dos artefatos e contextos materiais relacionados à educação escolarizada, a expressão não apenas amplia o seu significado reinserido as edificações, o mobiliário, os materiais didáticos, os recursos audiovisuais, e até mesmo as chamadas novas tecnologias do ensino, como também remete à intrínseca relação que os objetos guardam com a produção de sentidos e com a problemática da produção e reprodução social. (SOUZA, 2007, p. 170).

O estudo da cultura material escolar é um campo de investigação de suma importância para a problematização do universo escolar em sua complexidade, bem como da sociedade em seus diferentes tempos históricos, já que participa ativamente de sua construção cultural.

Assim, o estudo da cultura material escolar deve envolver uma série de questionamentos relacionados não só à função do objeto, mas ao sentido que é dado ao mesmo pelos sujeitos, seu uso, sua receptividade, sua aquisição, procedência, produção, custo, o motivo de sua escolha, sua ausência, enfim, uma gama de investigações que amplia o conhecimento histórico sobre educação (VEIGA, 2007).

Felgueiras (2010, p. 31) destaca que "[...] a cultura material escolar revela uma civilização que cria a escola e ao mesmo tempo a sociedade que é criada pela escola.” A autora afirma, ainda, que os materiais carregam um pouco de nós, à medida que atribuímos a eles afetos e significados para além de sua concretude, contribuindo para a constituição de nossa subjetividade, ao mesmo tempo, que nos revelamos por intermédio deles.

Destaforma, operiódicoelaborado pelaEscola Complementar Duque de Caxias revela em seus escritos, sua cultura, permitindo ver para além das letras, à medida que contribui para decifrar o que Julia (2001) chama de "caixa preta escolar". 


\section{Os impressos da "Duque": representações em destaque}

Em 1932, a Escola Complementar Duque de Caxias, como foi indicado anteriormente, criou três veículos para as comunicações internas, com o intuito de agregar alunos, professores, gestores e comunidade, dando-lhes voz e vez na construção de uma cultura escolar: "A Voz da Mocidade"; "Centelha"; e "Folha da Escola".

O jornal "A voz da Mocidade" tinha como objetivo valorizar e desenvolver as habilidades dos alunos com relação à escrita, sendo um espaço onde os jovens expressariam suas ideias em forma de redação, poesia, homenagem, humor, bem como informações diversas, tendo como intuito, também, de ser uma ponte entre alunos, professores e pais. Era de circulação mensal.

O jornal "Centelha" - também de circulação mensal - tinha como objetivo valorizar e estimular a escrita das alunas do curso normal, sendo um órgão exclusivo deste público.

Tinha, ainda, como objetivo ser um instrumento integrador entre os alunos, professores e com a própria comunidade. As páginas eram utilizadas para divulgar textos informativos, produções dos próprios alunos acerca dos estudos realizados, 'planos de lição', receitas, sínteses e ou comentários de obras literárias, notícias do Circulo de Pais e Professores, acontecimentos sociais da escola. (LUCHESE; BERGOZZA, 2009, p. 163).

O periódico "Folha da Escola" - objeto do presente artigo e também de circulação mensal - tinha como objetivo:

[...] unir os estudantes e aproveitar as vocações literárias, humorísticas e poéticas, que se manifestam entre os colegas e não seriam conhecidas de outra maneira, ou por timidez ou por falta de ocasião. Suas colunas estarão 
francas aos colegas e professores que queiram colaborar, auxiliando-os em nossas obras de unificação e dando-nos conselhos e sugestões que serão recebidos com prazer. Nele serão discutidos problemas relativos ao ensino, e tudo o que possa contribuir para a maior cultura cívica e literária da mocidade escolar. ${ }^{7}$

No jornal também eram publicadas produções dos alunos do colégio de aplicação, tendo, inclusive, circulação pelo Estado e até mesmo fora de suas fronteiras (LUCHESE; BERGOZZA, 2009).

Infelizmente, muitos exemplares foram perdidos ao longo do tempo, de modo que foi possível encontrar três edições, sendo uma de setembro de 1939 (número 1), outra de novembro de 1939 (número 2) e uma última de outubro de 1940 (número 3) (BERGOZZA, 2010).

Para a produção deste estudo, foi utilizado o exemplar publicado em outubro de 1940, comemorativo dos dez anos da escola. Analisando todos os exemplares, percebemos ser neste periódico que as redações foram publicadas em maior número, dando ênfase à temática "obediência".

A investigação do jornal "Folha da Escola" possibilitou adentrar num mundo de representações "expressos numa cultura material que, simultaneamente, traduz as concepções de uma sociedade e manifesta as condições que puderam ocorrer" (FELGUEIRAS, 2010, p. 29).

\section{Obedecer sempre!}

Ao folhear o jornal, foi possível observar que os primeiros textos versavam sobre pessoas e grupos "ilustres", como uma homenagem aos jesuítas; considerações sobre a visita da irmã 
Ester Gutierrez; e o que foi denominado de "formação do povo brasileiro: o negro, o índio e o branco". Em seguida, são apresentadas as redações elaboradas pelas crianças. A primeira, intitulada "Desobediência", diz:

\section{Desobediência}

Paulinho era um menino bonito, mas muito levado da breca. Ele tinha um irmão mais velho chamado José. Numa tarde, sua mãe foi passear e Paulinho procurou se divertir à vontade, fazendo muitas travessuras sem ouvir os conselhos do irmão. Uma delas foi mexer com os gansos que estavam quietinhos, eles ficaram furiosos e correram atrás do Paulinho que, muito assustado, foi agarrar-se ao irmão que ria muito. Depois abraçou o Paulinho e lhe disse: 'os meninos não devem ser desobedientes.' (Henrique Grossi, 9 anos) ${ }^{8}$.

O detalhamento do enredo do texto, associado às práticas cotidianas do universo infantil, possibilita refletirmos acerca da identificação entre os personagens, Paulinho, seu irmão José, sua mãe e os jovens leitores e seus familiares. Os conselhos dados por José e não ouvidos pelo "menino levado" acabaram resultando em ações e consequências exemplares para outras crianças, difundindo representações específicas em relação à desobediência.

Durkheim (1995), em sua teoria sobre a educação, afirma que a infância pressupõe um período de crescimento, tanto físico, quanto moral. A criança, de acordo com o autor, é um ser incompleto, débil, dotado - em sua natureza - de uma força de mudança, de transformação, uma pessoa em vias de formação; sendo ao mesmo tempo debilidade e movimento, indecisão e fugacidade. Assim, o dever do educador é saber trabalhar com tais dualidades, tendo como uma de suas incumbências ensinar a criança a dominar-se, controlar-se, conter-se, seguir as normas instituídas, discipliná-las, “[...] el domínio de si mismo, 
el poder de contenerse, de regularse, de retenerse, es uma de las características esenciales de la persona humana." (DURKHEIM, 1995, p. 26).

A ideia de disciplinar a criança para que siga as orientações do adulto por ela responsável está clara na redação destacada. Conforme Kant, é por meio da disciplina que o homem transforma a animalidade em humanidade, sendo ela que "[...] impede ao homem de desviar-se do seu destino, de desviar-se da humanidade." (KANT, 1996, p. 12).

Em outra redação, uma menina de 10 anos escreve:

\section{O menino guloso}

Antônio era muito guloso. Certo dia ganhou de presente um queijo, não querendo repartir com os irmãos, comeu um pedaço e guardou o outro no armário. E, quando voltou para comer o outro pedaço, viu um ratinho roendo-o. Ele ficou indignado com aquilo e foi buscar o gato e encerrou os dois dentro do armário. O gato comeu o rato e ainda comeu o queijo. Quando Antônio voltou, ainda viu o gato lambendo a barba. Foi castigo porque ele era muito guloso. (Geny Severo, 10 anos) $)^{9}$.

Tanto na primeira redação, quanto na segunda, os textos indicam uma relação de causa e efeito: se fizer X ocorrerá Y, ou seja, caso desobedeça, ocorrerá uma consequência, um castigo. A criança desobedeceu ao irmão, foi atacado pelos gansos; o menino não quis repartir o alimento, ficou sem ele. Há, em ambos os casos, um componente de ameaça: se fizer... se desobedecer...

No texto que segue, a ameaça como forma de controle também é explicitada, apontando consequências ainda mais intimidadoras. 
A menina curiosa

Ana tinha pouco mais de 6 anos. Era uma menina muito bonita, mas tinha mau hábito de ser curiosa. Tudo o que se passava ela queria saber. Quando houvida qualquer cousa na rua, subia a uma cadeira e olhava. Certa vez, a criada estava arrumando a sala, quando Ana ouviu falar alto na rua. Encostou a cadeira à janela, como de costume, mas desta vez se inclinou de tal maneira que perdeu o equilíbrio e caiu. A criada correu em seu socorro mas chegou tarde. Ana quebrou uma perna e ficou aleijada para sempre. (Tatiana Magdalene, 11 anos) ${ }^{10}$.

A curiosidade excessiva acabou sendo punida severamente e de forma irreversível no caso da redação de Tatiana Magdalene. Ficamos com a pergunta: a curiosidade era um "mau hábito" que deveria ser punido apenas nas meninas ou o rigor em relação a uma atitude, plenamente compreensível nas crianças, também atingia os meninos? Mais uma vez, a narrativa infantil de cunho moralizante lembra os jovens leitores da necessidade do autocontrole e sua ausência poderia acarretar danos marcantes.

Para Herbart (1983), a educação moral, que forma a vontade, é imprescindível para a formação da criança. Segundo o autor, o governo das crianças tem como finalidade prevenir o mal, tanto para os outros, quanto para ele, em todos os períodos da vida, a fim de estabelecer a ordem e permitir uma melhor convivência coletiva.

A criança, de acordo com Herbart (1983), mesmo não tendo capacidade de tomar decisões - por não ter uma moral desenvolvida - possui uma natureza cujo princípio é a desordem, necessitando ser "domada" por intermédio da ameaça, sendo este o primeiro procedimento para seu governo; acompanhada da vigilância, da autoridade e do amor. "La amenaza, sancionada en caso de necessidad por la coacción; La vigilancia, que prevé en general lo que pudiera ocurrir a los niños, la autoridad y el amor: todas estas fuerzas reunidas bastarán, hasta cierto punto, 
para asegurar-se el dominio sobre los niños [...]." (HERBART, 1983, p. 35).

Na redação abaixo, mais uma vez a desobediência acarretou consequências desagradáveis:

O rato e o gato

Era uma vez um rato que estava sendo vigiado por um gato. $\mathrm{O}$ ratinho, sempre prudente, não ousava sair do buraco, pois já tinha ouvido sua mãe falar que o gato é o maior inimigo dos ratos. Mais tarde, o rato deu um espirro e o gato disse: 'Deus te dê muitos anos de vida, querido ratinho'. Então o rato pensou: se eu fosse fazer uma visita? E saiu do buraco, mas o gato, que é um bicho esperto, estrangulou-o. (Clovis Motta, 9 anos) ${ }^{11}$.

A atribuição de características humanas aos animais em narrativas moralizantes é uma prática presente em diversos autores, citados anteriormente, reconhecidos em fábulas e contos, em períodos históricos diversos. No caso do "rato e do gato" de Clóvis Motta a desobediência resultou em uma surpresa irreversível.

$\mathrm{Na}$ visão de Herbart (1983), é fundamental que haja primeiramente o governo, ou seja, um controle externo para, gradativamente, a criança internalizá-lo, convertendo-se em autodisciplina. Para o autor, a disciplina tem a função de formar o sujeito, devendo acompanhá-lo em diferentes períodos da vida, possibilitando sua participação no mundo. De acordo com o pensador, sem governo e disciplina não é possível que haja educação e instrução.

Spencer (1888, p. 200) também advoga a ideia da autodisciplina quando afirma que "[...] o fim da educação moral é formar um ser apto para governar a si mesmo e não um ser apto para ser governado pelos outros." Defende ainda que a educação por meio das consequências naturais dos atos - ou, como aponta o autor, "sistema de educação moral pela experiência das reações 
naturais" (SPENCER, 1888, p. 179) - mostra-se mais eficaz do que o avilte físico e as palavras humilhantes. Conforme Spencer (1888, p. 173):

Entre as vantagens que oferece esse sistema nós vemos: em primeirolugar que ele ministra ao espírito, em matéria de conduta, essa noção justa do bem e do mal que resulta da experiência dos efeitos bons e maus; em segundo lugar, que a criança, não experimentando mais do que as consequências penosas das suas ações, deve reconhecer mais ou menos claramente a justiça da penalidade; em terceiro lugar, sendo reconhecida a justiça do castigo e sendo este aplicado pelas mãos da natureza e não pelas de um indivíduo, a criança experimenta dessa forma menos irritação [...].

Nos textos anteriores, todas as crianças sofreram uma consequência natural dos atos: mexeu com gansos, foi atacado; não repartiu o alimento, ficou sem ele; debruçou-se na janela por ser curiosa, caiu e quebrou a perna; não confiou nos avisos maternos, foi estrangulado.

Para Spencer (1888), o ensino da moral está ligado ao caminhar da natureza. Entender o certo e o errado vincula-se ao prazer e ao desprazer que seu ato naturalmente impõe. Não se relaciona às "explosões parentais", ao uso de instrumentos de castigo físico ou a verbalizações humilhantes, mas às consequências naturais dos erros. O sofrimento da criança está no ato em si. Sobre a educação natural, o autor advoga que:

Uma das vantagens é que a sua aplicação produz no espírito noções justas de causa e efeito, noções que experiências repetidas mais tarde tornam definitivas e completas. É fácil conduzirmo-nos bem na vida quando se compreendem as boas e as más consequências destas 
ações, mais ainda do que se acredita na autoridade dos outros. (SPENCER, 1888, p. 173).

Nas redações destacadas, as mensagens buscam incutir no imaginário da criança a ideia de que a desobediência leva naturalmente - a consequências desagradáveis.

Condorcet (1943) concordava com o uso das histórias na educação moral das crianças e afirmava que a educação moral deveria estar baseada em princípios racionais, tendo "[...] como finalidade fortalecer os hábitos virtuosos e prevenir ou destruir os outros." (CONDORCET, 1943, p. 160). A recomendação de Condorcet (1943), nesse sentido, envolvia imprimir o sentimento de vergonha e constrangimento no aluno, para que não voltasse a cometer o ato impróprio, não bastando, portanto, "apenas" as consequências "naturais" dos atos.

Acreditava que tanto a escola quanto a família teriam a incumbência de formar moralmente a criança. Na família, o foco está na ação materna, servindo de exemplo para seus filhos. Na escola, a ênfase é posta nas histórias contadas por professores, equilibrando sensibilidade e racionalidade, para que a preocupação do sujeito fosse além de seu núcleo familiar, mas envolvesse toda a humanidade. Para Condorcet (1943), as histórias são capazes de desenvolver sentimentos de empatia, à medida que colocam as crianças nas situações dos personagens, a fim de vivenciarem - na imaginação - suas experiências, sendo fundamental para despertar os primeiros sentimentos morais.

Ao escrever sobre situações de desobediência, afirma o autor, a criança está elaborando - numa esfera psicológica - os preceitos ensinados pelos adultos, como se estivesse fixando uma mensagem (CONDORCET, 1943).

Interessante notar que em todos esses discursos - seja no dos pensadores, seja nos infantis - há justamente um movimento de fixar uma mensagem a fim de civilizar a criança para que 
possa viver em coletividade, respeitando as regras sociais. Neste sentido, civilizar pressupõe uma mudança de comportamento em direção ao controle dos sentimentos, traduzido no corpo, hábitos e costumes. Educar moralmente passava pela esfera da civilidade, o que demandava intenso processo de aprendizagem iniciado desde tenra idade, por meio de controles externos, como manuais de etiqueta, regras de conduta e discursos moralistas (ELIAS, 1994).

As histórias contadas para as crianças e, posteriormente, reproduzidas em forma de redação representam a necessidade da escola em educar as crianças na senda da obediência aos adultos e às regras de convivência. Conforme Elias (1994, p. 30, grifos do autor), “[...] a criança não é apenas maleável ou adaptável em grau muito maior que os adultos. Ela precisa ser adaptada pelo outro, precisa da sociedade para se tornar fisicamente adulta." Torná-la adulta, na visão do autor, seria tirá-la da condição de ser instintivo e humanizá-la, em outras palavras, proporcionar sua inserção na cultura de modo que fosse possível sua convivência com os demais membros da sociedade.

\section{Palavras finais: um jornalzinho com algumas intenções!}

A vida moral do homem é governada por certo número de regras, de princípios, como afirma Durkheim (1995), que direcionam as ações pessoais e grupais, assinalando como devemos agir em coletividade. A moral, portanto, é um sistema de regras que possibilita o relacionamento entre os sujeitos, sendo de suma importância para a convivência coletiva, conforme aponta Elias (1994).

Herbart (1983) entra nessa discussão frisando que a educação moral visa desenvolver na criança, além da convivência, a 
inteligência, juntamente com a vontade. Assim, defende que o primeiro passo é o seu governo - heterônomo - até que o sujeito seja capaz de internalizar os preceitos morais, culminando na autodisciplina, fruto do amadurecimento.

Spencer $(1888$, p. 21) acredita que o valor de uma sociedade depende do caráter de seus cidadãos, sendo a educação o "meio mais certo de influir sobre o caráter." Todavia, para o autor, não há necessidade de "preparar a juventude para os deveres da vida" (SPENCER, 1888, p. 148) com açoites ou palmatórias, mas com uma educação natural, ou seja, através das consequências naturais dos atos.

Seguindo a mesma linha, Condorcet (1943) advoga sobre a importância da educação moral para o desenvolvimento da criança, pois é por intermédio da formação moral que o sujeito poderá exercer sua autonomia, sem depender do governo ou religião para conduzir suas escolhas.

As redações escritas pelas crianças apresentam o resultado de uma educação voltada para o ensino de preceitos morais, tal como defendem os autores supracitados. Neste sentido, a primeira regra a ser aprendida versa sobre a obediência ao adulto, caso contrário, as consequências "naturais" dos atos de desobediência serão sentidas. O governo da criança, em suas redações, se faz com forte tom ameaçador, mas que esconde, também, um caráter de proteção: na redação sobre o gato e o rato, observa-se uma tentativa de afastar a criança do contato com estranhos e na redação da menina curiosa, percebe-se a necessidade de proteger a criança da queda. Mas, também, os registros infantis reforçam que a punição pela curiosidade e pela desobediência pode ser irreversível.

Independentemente do motivo ou do tom que tenham as redações, elas apontam para a preocupação da Escola Complementar Duque de Caxias, através do seu impresso, em educar a criança na virtude, na obediência, no respeito à família 
e aos "mais velhos", afinal, é por meio de educação moral que o sujeito pode participar de forma eficaz da vida social, conforme os autores visitados.

Todavia, ao divulgar as redações dos alunos, a referida escola constrói, também, uma imagem de escola, aquela preocupada não só em educar intelectual ou fisicamente as crianças, mas também abarcando o aspecto moral e mais: incorporando a família neste processo, à medida que todos os temas envolvem algum membro da casa.

A publicação e circulação do jornal para além das fronteiras escolares confluem para uma maior preocupação com a imagem da escola e com o que ela pretendia divulgar sobre a educação que ministrava às suas futuras professoras - em especial sendo o jornal analisado, comemorativo dos dez anos da escola - o que, de valor, ela transmitia para as estudantes e estas para seus pequenos alunos. Cabe salientar que a escolha dos textos, bem como sua revisão, passava pelas mãos do conselho editorial, formado por professoras e normalistas. Assim, a publicação destes textos não foi aleatória, mas divulgava uma visão de educação construída "a muitas mãos", ou seja, a partir da circularidade e apropriação de diferentes discursos, além de servir aos interesses da instituição que o produz e divulga.

As redações transcritas parecem representar o que ficou de significativo para a criança-autora a partir das histórias (de qualquer gênero literário) que ela ouviu nos diferentes espaços de socialização por onde passou. A partir dos textos publicados, verificamos um intenso diálogo entre os elementos da cultura escolar e das culturas infantis, que ficou como pauta para outros estudos, assim como as questões de gênero e de diversidade cultural.

Interessante, todavia, é transitar "daqui para lá", isto é, adentrar no universo infantil, tendo em vista que este também é lugar de produção de cultura, de formação de valores e de 
sedimentação de práticas e comportamentos. Sentimos que vale a pena questionar como a criança constrói sentidos para o mundo que a rodeia, o que ela incorpora do universo que vive e de que maneira transmite a cultura que vivencia, bem como tentar identificar como a instituição escolar estimula, valoriza e premia atitudes, no caso deste estudo, publicando redações selecionadas que por si só advertem, controlam e punem atos indesejados e posturas condenáveis.

\section{Referências}

ANTUNES, Duminiense Paranhos. Documento Histórico do município de Caxias do Sul: 1875-1950. Caxias do Sul: Prefeitura Municipal de Caxias do Sul, 1950. Disponível na Biblioteca Setorial da Unisinos/RS.

BERGOZZA, Roseli. Escola Complementar de Caxias: histórias da primeira instituição pública para formação de professores na cidade de Caxias do Sul (1930-1961). 2010. 174 f. Dissertação (Mestrado em Educação) - Centro de Filosofia e Educação, Universidade de Caxias do Sul, 2010.

CAMBI, Franco. História da Pedagogia. São Paulo: Unesp, 1999.

CHARTIER, Roger. Entre práticas e representações. 2 ed. Lisboa: Difel, 2002. (Coleção memória e sociedade).

CONDORCET, C. Instrução pública e organização do ensino. Porto: Livraria Educação Nacional, 1943.

DURKHEIM, Émile. Educación y Pedagogia: ensayos e controversias. Porto Alegre: Artes Médicas, 1995. 
ELIAS, Norbert. O processo civilizador. Rio de Janeiro: Jorge Zahar, 1994. v. 1.

FELGUEIRAS, Margarida Louro. Cultura escolar: da migração do conceito a sua objetivação histórica. In: FELGUEIRAS, Margarida Louro; VIEIRA, Carlos Eduardo (Eds.). Cultura escolar, migrações e cidadania. Porto: Sociedade Portuguesa de Ciências da Educação e autores, 2010. p. 17-32.

HERBART, J. F. Pedagogia general derivada del fin de la Educación. Barcelona: Humanitas, 1983.

JULIA, Dominique. A cultura escolar como objeto histórico. Revista Brasileira de Educação. Campinas: Editora Autores Associados, n. 1, p. 9-43, jan./jun. 2001.

KANT. Sobre a Pedagogia. Trad. Francisco Fontanella. Piracicaba: Unimep, 1996.

LUCHESE, Terciane Ângela; BERGOZZA, Roseli Maria. Histórias da "Duque" a partir de seus impressos: a Escola Complementar Duque de Caxias - 1930 a 1945. In: TAMBARA, Elomar; CORSETTI, Berenice (Orgs.). Instituições formadoras de professores no Rio Grande do Sul. 1. ed. Pelotas: Editora da Universidade UFPel, 2009. v. 3. p. 145-175.

SOUZA, Rosa Fátima de. História da Cultura Material Escolar: um balanço inicial. In: BENCOSTTA, Marcus Levy (Org.). Culturas escolares, saberes e práticas educativas: itinerários históricos. São Paulo: Cortez, 2007. p. 163-189.

SPENCER, J. F. Educação: intellectual, moral e physica. Trad. Emydio de Oliveira. 2. ed. Porto: Alcino Aranha \& Cia, 1888.

VEIGA, Cíntia Greive. História da Educação. São Paulo: Ática, 2007. 
VIÑAO FRAGO, Antônio. História de la educación e historia cultural. Revista Brasileira de Educação, São Paulo, n. 0, p. 63-82, set./dez. 1995.

\section{Fontes}

JORNAL "FOLHA DA ESCOLA", ano 2, n. 8, p. 1-4, out. 1940. Depositado no Acervo no I.E.E. Cristóvão de Mendoza.

\section{Notas}

${ }^{1}$ Psicóloga, mestre em Educação, doutoranda do Programa de Pós-Graduação em Educação da Universidade Federal de Sergipe. Bolsista FAPITEC/SE. E-mail: <mi.aragao@yahoo.com.br>.

${ }^{2}$ Pós-doutora em Educação. Professora do Programa de Pós-Graduação em Educação da Universidade Federal de Sergipe. Vice-coordenadora do Grupo de Estudos e Pesquisas em História da Educação: intelectuais da educação, instituições educacionais e práticas escolares.E-mail:<anagbueno@uol.com.br>.

${ }^{3}$ São pensadores que viveram em diferentes períodos históricos, do século XVIII ao século XX, mas que deram contribuições significativas para pensar as relações entre educação, sociedade e formação moral: Emile Durkheim (1858-1917), sociólogo alemão; Johann Friedrich Herbart (1776-1841), filósofo e pedagogo alemão; Spencer (1820-1903), educador inglês; Marie Jean Antoine Nicolas de Caritat, o Marquês de Condorcet (1743-1794), educador e político francês; Norbert Elias (1897-1990), sociólogo alemão.

${ }^{4}$ Decreto do Governo do Estado do Rio Grande do Sul, sob o n. 4491, de 28 de fevereiro de 1930.

${ }^{5}$ Salientamos que a Escola Complementar Duque de Caxias mudou sua designação ao longo dos anos, passando a "Escola Normal Duque de Caxias", posteriormente a "Colégio Estadual Cristóvão de Mendoza" e, desde o ano de 2000, chama-se "Instituto Estadual Cristóvão de Mendoza". 
${ }^{6}$ Luchese e Bergozza (2009) realizaram um estudo sobre tais impressos, no texto intitulado: "Histórias da 'Duque' a partir de seus impressos: A Escola Complementar Duque de Caxias 1930 a 1945", elas apontam detalhes sobre sua circularidade, custo, forma de exposição, número de páginas, redatores, local de abrangência, entre outras informações. Neste artigo não trataremos dos impressos, mas das representações sobre a função e o perfil docentes presentes nestes jornais.

${ }^{7}$ Jornal "Folha da Escola", ano 1, n. 1, p. 1, set. 1939. Depositado no Acervo no I.E.E. Cristóvão de Mendoza.

${ }^{8}$ Jornal "Folha da Escola", ano 2, n. 8, p. 3, out. 1940. Depositado no Acervo no I.E.E. Cristóvão de Mendoza.

${ }^{9}$ Jornal "Folha da Escola", ano 2, n. 8, p. 3, out. 1940. Depositado no Acervo no I.E.E. Cristóvão de Mendoza.

${ }^{10}$ Jornal "Folha da Escola", ano 2, n. 8, p. 4, out. 1940. Depositado no Acervo no I.E.E. Cristóvão de Mendoza.

${ }^{11}$ Jornal "Folha da Escola", ano 2, n. 8, p. 4, out. 1940. Depositado no Acervo no I.E.E. Cristóvão de Mendoza. 